\title{
ART FOR A NEW CONSCIOUSNESS, ART FOR A NEW HUMANITY: AN EMPIRICAL INVESTIGATION OF AESTHETIC EFFECT OF KAMRAN KHAVARANI'S PAINTINGS
}

\author{
PARISA AMIRMOSTOFIAN, SIMIN MOZAYENI
}

\begin{abstract}
:
Our hypothesis is that Khavarani's painting style, Abstract Romanticism, combines artistic elements that impart positive effect on viewers' psyche. Our data encompass survey of 318 viewers' responses, recorded in six Likert scales. We used Random Group Design to administer and organize the data. Our estimation results, using the Friedman, Mann-Whitney and Kruskal-Wallis tests, produced $\chi 2$ values, which confirm our hypothesis with $95-100 \%$ confidence. We conclude that Khavarani's paintings impart positive effect on viewers' psyche. In a future study, we'll report that such effect is independent of viewer's age, gender, and their base mood. We invoke Vartanian and Skov (2014): When our subjects viewed Khavarani's paintings, they "maximized the utility of the moment" and "disengaged" from their external world. We recognize that as experiencing meditative joy.
\end{abstract}

\section{Keywords:}

Khavarani, Abstract Romanticism, Meditative Effect of Painting, Behavioral Economic

JEL Classification: C35, C90, Z11

\section{Authors:}

PARISA AMIRMOSTOFIAN, NONE, USA, Email: parisa@parisaarttherapy.com SIMIN MOZAYENI, SUNY New Paltz, USA, Email: mozayens@newpaltz.edu

\section{Citation:}

PARISA AMIRMOSTOFIAN, SIMIN MOZAYENI (2016). Art for A New Consciousness, Art for A New Humanity: An Empirical Investigation of Aesthetic Effect of Kamran Khavarani's Paintings. International Journal of Social Sciences, Vol. V(1), pp. 27-46., 10.20472/SS.2016.5.1.002

Contributions:

(1) Amirmostofian: The research question, conception and design of the data, acquisition of data, coding and entry of data, review and approval of manuscript drafts. (2) Mozayeni: Literature review, design of data subgroups, verification of raw and coded data, statistical methodologies and execution, interpretation of data, drafting the manuscript and its revisions, journal submission and follow-up work. 
Acknowledgments:

(1) We acknowledge research support from Dr. Einat Metzl, Associate Professor of Art Therapy, and the Chair of the Alumni Research Advising Committee (2013-14) at Loyola Marymount University in Los Angles, California. We have benefitted from her advice for the design of the material, procedure and the survey questionnaire. In addition, she guided the direction of the research question in the early stages of our research. (2) We also acknowledge competent and dedicated research assistance of Ms. Rui Wang, a Senior Economics major (2014-15) at the State University of New York at New Paltz. Under supervision of Prof. Mozayeni, she conducted estimation of the models for this research.

Statement of Conflict of Interest:

The authors have NO affiliations with or involvement in any organization or entity with any financial interest (such as honoraria; educational grants; participation in speakers' bureaus; membership, employment, consultancies, stock ownership, or other equity interest; and expert testimony or patent-licensing arrangements), or nonfinancial interest (i.e., professional relationships, affiliations, knowledge or beliefs) in the subject matter or materials discussed in this manuscript. 


\section{Introduction}

We test the hypothesis that Khavarani's painting style, known as Abstract Romanticism, combines artistic elements that impart positive effect on individuals' psyche, thus their mood. This research is motived by multiple factors. First, we had firsthand observation of the effect of Khavarani's paintings on enhancement of "mood" for several years. Second, we were provoked by numerous testimonials by viewers of his paintings over a decade long. Third, Boime's (2008) proposition that Khavarani's painting style has artistic characteristics that impart positive effect on individual's mind begged for an empirical research. In these contexts and the Aesthetical literature, we pursue our hypothesis.

The importance of the effect of visual arts on the human brain has been for long the subject of inquiries in psychobiology, social psychology, neurology, and more recently in neurasthenics. Numerous studies have examined the aesthetic effects of color, shape and lighting in space design on the human psyche. Several have specifically evaluated the effect of paintings on the human brain.

The literature generally falls on two distinct tracks, namely, theoretical or empirical. A few have formulated their empirical observations to develop a theory. Irrespective of their focus and methodology, they amass strong evidence that visual arts stimulate the brain and affect viewers' psyche, and thus mood. We review both the theoretical and empirical aesthetic literature, which have mostly emerged in the last 10 years, almost in parallel. Although, the advent of fMRI technology has facilitated direct observation of the effect of art stimuli on the human brain, the survey method has eased the research administratively and economically. According to the joint study by Johns Hopkins' Brain and Mind Center and the Walter Museum, noted in Vikan (2010), these two methods produce "identical" results. Their finding unifies the two method of empirical research.

The old and new notable theoretical works in aesthetics include: Tolstoi (1897-98], Berlyne (1965, 1971 and 1974), Ramachandran and Hirtstein (1999), Zeki (1999), Solso (2003), Reber and Schawarz (2004), Silvia (2005), Anjan and Vartanian (2011), Ishuzi and Zeki [2011], Gopnikc (2012), Hager and associates (2012), Kendal (2012), Vartanian and Skov (2014), among others.

Major empirical works in aesthetics over the last decade include: Cela-Conde (2004), Kemp and Cupchick [2007], Silvia [2007], a joint study by the Johns Hopkins Brain and Mind Center with Walter Museum (2010), Lacey and associates (2011), Tsuklura and Gabeza (2011), Zeki (2011), Vessel (2013), and Vartanian and Skov (2014).

The common theme that emerges from these works clearly point to evidence that the human brain responds to certain characteristics in visual arts, being beauty or ugliness. In that way, arts affect the human life. Berlyne (1971) noted that art has always been an 
instrument for beatifying life in all 3,000 cultures of the world. He thus suggested that the value of art must be measured by its effect on human life. He unequivocally submitted: "...effectiveness of a work of art invariably hinges quite subtly on how much a certain quality is present." (p. 5). For measurement of such effect, he proposed a five-point maxim for judging the quality of art. (p. 61), which has provoked many more inquiries in the field.

Berlyne in a different work (1974) noted that work of art is analyzed in informationtheoretical terms, as collection of all its elements, each of which can transmit information from four distinct sources: semantic information, expressive Information, cultural Information and syntactic Information; together they define the characteristics and the elements of a work of art. (p. 9). Closely related, he noted, are: (1) Characteristics of an external object, (2) psychological process within the artist, (3) social norm and (4) characteristics of other elements of the same work. To him, these elements determine the value of a piece of art.

In Berlyne, et al. (1974), he referenced his earlier work, Berlyne (1967), where he connected hedonic values of paintings with fluctuation in arousal. He hypothesized that aesthetic patterns produce their hedonic effects by acting on arousal-a counterpart of the previous conviction that works of art give pleasure through their emotional impact. [p. 8]. Berlyne laid the foundation for "measuring" the aesthetic effects of a painting. That seemed to be the first step towards having a universal standard for assessing visual arts objectively. Subsequently, an urge has emerged in quest for deeper understanding of what makes an art beautiful.

Yet, for centuries, the question of what beauty is has struggled with determining an adequate definition. Some observers have sought to understand beauty in terms of the characteristics of the objects. It has been suggested that in visual art (e.g., architecture), symmetry, proportion, harmony and so on, may summarize "beauty." Ramachandran, one of the two pioneers in the field of Aesthetics, with Hirstein, identified symmetry and "balance" among ten elements (later, eight elements) present in great paintings, which attract people to their beauty, Ramachandran and Hirstein (1999). They presented a theory of human artistic experience related to neural mechanism. They suggested that artists either consciously or unconsciously deploy certain rules or principles (laws) to excite the visual areas of the brain. They presented many of those laws together and provided a coherent biological framework that when considered simultaneously, and viewed in a biological context, begin to make sense. They saw three bases to their argument. First, what might loosely be called the "internal logic" of the phenomenon they called laws. Second, the evolutionary rationale: the question of why the laws have evolved and have that particular form (e.g. grouping facilitates object perception). Third, the neurophysiology (e.g. grouping) occurs in extra striate areas and is facilitated by synchronization of spikes and direct limbic activation. All three of these need to be 
present; and must inform each other, before one can claim to have understood any complex manifestation of human nature, such as art. Many earlier discussions of art, in their view, suffer from the shortcoming of viewing the problem from just one or two of these perspectives. According to their theory of art, evaluation of an artistic object must have at least three components: (a) the logic of the art and universal rules or principles for their evaluation; (b) the evolution of the rationale; (c) and determination of the brain circuitry involved. Thus, they proposed eight laws of "artistic experience," as the key characteristics of arts.

Semir Zeki, also one of the founders of the Aesthetics (with Ramachandran), developed an outline of a theory of aesthetics that is biologically based, Zeki (1999). He considered that work an outline since he thought that the knowledge of how actually brain works was still very sketchy then. Yet, he noted, "all visual arts obeyed the law of brain and must therefore obey the laws of the brain." He said, "... art is an active process, whose function constitutes an extension of the function of the visual brain." (p. 7).

Solso [2003] connected evolution of conscious thought with the evolution of art. His basic thesis was that when humans evolved conscious awareness, they were able to make conscious association between pleasurable experiences and stimuli. That empowered people to value art.

Reber and associates (2004) asked, "what is beautiful," going back to Plato. They proposed that aesthetic experience is a function of the perceiver's processing dynamics. They noted three factors, which emerge from their literature review: goodness of the form, symmetry and figure-ground contrast, which "protypically" creates fluency in a painting. Accordingly, they suggested that these elements are at the heart of creating aesthetic pleasure.

Silvia (2005) gave a historical perspective and emphasized the importance of the modern science of "emotions," because it has much to offer the study of aesthetics, opening an expansive set of new ideas. He suggested that appraisal of theories make new predictions about emotional responses to art, expanding the domain of aesthetic emotions beyond positive emotions such as interest and enjoyment. He developed the Model of Appraisal and Interest in Art that informed the study of aesthetics.

Silvia, et al., also proposed that spectators of paintings differ in emotional response to art-which challenges the arousal model. Their artistic training affects their judgment. Knowledge about art affects the emotional experience of art. Emotional concepts within the Berlyne (1971) tradition, however, have emphasized affective terms such as preference, reward value, aesthetic response, hedonic response and affective response. $\mathrm{He}$ also observed that would be unproductive to lump different emotions, each with distinct causes and consequences, under one umbrella. Besides, Silva noted that according to some studies the rating of interest differs from rating of enjoyment. (p. 351). 
Based on these findings, he suggested an alternative Arousal Model, following in the footsteps of Berlyne, et al.

Dutton (2009) suggested an interesting and fascinating view that arts are by-products of an evolutionary adaptation, which is an instinctual trait. Therefore, arts help us to survive because they are critical to our wellbeing.

Ishizu and Zeki (2011) developed the Brain Theory of Beauty. They addressed the question that has been asked for many centuries, namely what constitutes beauty. They note that Burk (1757) suggested "Beauty is, for the greater part, some quality in bodies acting mechanically upon the human mind by the intervention of the senses." Ishizu and Zeki. (p.1). They concluded that this definition suggests presence of a consciousness of beauty that can be stimulated by any and all senses. But their reading of the relevant humanistic literature suggested that the first alternative has been more favored by those who have debated on the subject, namely that there is a single faculty of beauty into which different senses feed. Yet, they believed that alternative was echoed in Burke's definition. Overall, their research was motivated to explore how brain activity might be organized during the experience of beauty. They investigated whether beauty from different sources activated the same areas of the brain. Their data comprised 21 subjects' brain responses to stimuli (paintings and excerpts of music), using fMRI imaging. They selected three sets of stimuli- "beautiful," "indifferent" and "ugly," in each category. They concluded that there is a faculty of beauty that does not depend on modality through which it is conveyed. In their experiment, at least two sources of stimuli (and probably other sources, they note) had the same effect on their subjects. These findings led them to formulate their "brain theory of beauty."

Gopnikc (2012), focused on the biological bases of human behavior. He concluded that aesthetic experiences emerge from the interaction between sensory-motor, emotionsvaluation, and meaning, encompassing knowledge neural systems.

Hager and associates (2012) conducted two studies, using 193 cases in one and 147 in another, for their experimentation. They analyzed factor structure of an aesthetic experience and developed the Art Reception Survey (ARS), which is a template for assessment of characteristics of an artwork. They identified a 6-factro structure, including recipients' cognitive involvement, positive or negative affective appraisal and creativity, and information about knowledge and comprehension about artwork for judgment of pleasure, likeability, or beauty.

Eric Kendal, a 2000 Nobel laureate, suggested in Kendal (2012) that human brain assigns meanings of different degrees to the various shapes, colors and movement seen in a beautiful artwork. He noted, those effects illustrate that the aesthetic pleasure is not an elementary sensation (like the feeling of hot or cold, or the taste of bitter or sweet). He noted that they represent a higher-order evaluation of sensory information, processed 
along specialized pathways in the brain that estimate the potential for reward from work of art that people view. Kendal noted that sudden recognition of an $A H A$ moment by the viewers of art is because they suddenly see the artist's communication shared with them. They see that creative process, which characterizes every human brain, leads us to see the truth underlying both the beauty and the ugliness depicted by the artist. (E book: Loc 5019 of 9484$)$.

Vartanian and Skov (2014) focused on the visual modality and paintings to evaluate aesthetic experience associated with exposure to works of art. They selected 15 studies through Boolean searches in Pub-Med (p. 53) to conduct a quantitative metaanalysis of $15 \mathrm{fMRI}$ studies of response to paintings. Of the fifteen studies they used, 13 had a small number of subjects, 8-21, with remaining two of larger numbers, 40 and 87 cases. Yet, Vartanian and Skov created a large sample, integrating all of those cases. They used the Activation Likelihood Estimation (ALE). They confirmed that viewing paintings engages not only systems involved in dual representation and object recognition, but also structures underlying emotions. They confirmed three hypotheses that: (1) viewing paintings activates areas in the visual cortex including "the lingual gyrus and the middle occipital gyrus, as well as the fusiform gyrus." They noted that these activations could be attributed to the processing of various features of the stimuli embedded within paintings; (2) the stimulating effect of "representations," such as landscapes, in paintings on the brain (3) the activation of the anterior insula bilaterally. The most interesting, and somewhat unexpected, result of their study was finding activation in the posterior cingulate cortex bilaterally. They noted that this region is affected when viewers "maximize the utility" of being in the "moment" (while viewing a painting), and "disconnect themselves" from their external world. Their third finding suggests that paintings may have a powerful effect on perceptive viewers' inner emotions and thoughts. The same logic suggests that paintings can have a meditative effect, as mediation defined in the Merriam-Webster dictionary.

The theoretical literature we have reviewed support a major proposition that paintings are stimuli to the human brain, and can indeed immerse the viewers in moments of pleasure when they encounter a positive aesthetic experience. This literature supports our presupposition that Abstract Romanticism has affective properties that impart positive emotional effect on viewers.

Along with the theoretical Aesthetics research, empirical knowledge has also moved notably on a fast trajectory in the last ten years. Recent methodology has expanded research to development of the Neuroaesthetics field by focusing on the viewers' experience with beauty and appreciation of arts at the levels of brain function. In this line of research, it is widely accepted that visual aesthetics, namely the capacity of assigning different degrees of beauty to certain forms, colors, or movements, is an innate human trait. The empirical research also indicates that when viewers of paintings perceive them 
beautiful, their brain is stimulated. Among them are: Cela-Conde (2004), Kemp and Cupchick (2007), Silvia (2007), a Joint study by Johns Hopkins Brain and Mind Center and the Walter Museum (2010), for which we have found no journal publication record, Lacey and associates (2011), Tsuklura and Gabeza (2011), Ishuzi and Zeki (2011), Vessel [2013], and Vartanian and Skov [2014].

Studies of the human brain response to the arts (e.g., visual arts) use either self-reported responses of the subjects in an experiment or directly observe subjects' brain responses to stimuli, using $\mathrm{fMRI}$, albeit substantial financial and administrative cost differences. With the advent of technology, the latter has become the predominant method. We review both methodologies and address.

Cela-Conde (2004) used magnetoencephalography (MEG) on eight (8) university students to study the localization of brain areas activated during the visual perception of aesthetic objects. That research found that activation of the Prefrontal Cortex in the Human Visual Aesthetic Perception, tied the human experience (the determination of specific brain circuitry involved) points to understanding of the origin of the human response to beauty.

Silvia (2005) evaluated the modern science of "emotions" and how appraisal theories of emotion inform the study of aesthetics, making new predictions about emotional response to arts, within the Berlyne's tradition.

Kemp and Cupchik (2007) used the survey method to examine the effect of a selection of paintings on the human mind. Their data included 48 undergraduate students enrolled in a Psychology course at the University of Toronto, who received course credit for their participation. They recorded the subjects' mood before the experimentation weekly and after their viewing of a selected set of paintings. In sum, they examined the ways that the subject matter and style can predict emotional experiences of artworks, particularly when viewers' individual differences in their study were taken into account. To the best of our knowledge, this work is one of very few studies based on a survey method. Unfortunately, their very small sample size and highly specific population, hinders generalization of their results. Nonetheless, their findings are congruent with the theoretical aesthetic literature we have reviewed.

Silvia and Brown (2007) also used a survey method with similar sample limitations. Their sample included fifty-eight (58) undergraduate students. They conducted a multi-level analysis, observing anger, disgust and negative aesthetic emotion responses to artwork. They concluded that these emotions are central to individuals' appraisal of art, why people reject or embrace artworks. Their sample had the same limitations as the Kemp and Cupchick's, et al. 
On the other hand, several studies have used fMRI. These studies, in general, have a small sample due to the nature of the work involved. Therefore, their results cannot be generalized.

Lacey and associates (2011) studied the responses of eight (8) subjects to 50 paintings and observed their effect on their brains. Participants liked art images more than non-art images. They suggested that responses to one questionnaire did not necessarily influence responses to another and that these aspects of esthetic experience were independent for non-art images while, for art images, esthetic pleasure was independent of the other ratings. They corrected for the limitation of their small sample size to be able to generalize it.

Tsuklura and Gabeza (2011), based on their study of 22 subjects, successfully encoded the brain responses to stimuli (painting and excerpt of music) activity. They reached three results: (1) activity in the right orbitofrontal cortex increased (linearly) as a function of attractiveness rating; (2) activity in the left hippocampus increased as a function of subsequent memory; (3) functional connectivity between these orbitofrontal and hippocampal regions were stronger during encoding of attractive faces, leading to activation of regions associated with reward and memory. They clearly observed activation of the regions of brain associated with reward and memory and thus a positive bias toward attractive faces, and beauty in general.

Vessel (2013) used fMRI to scan the brain of sixteen (16) subjects. All of them saw the same series of 109 color artworks in a randomized manner. They investigated the differences in subjects' aesthetic responses to address the shortcomings they perceived of in previous neurasthenics research. In their opinion, those researchers "tended to utilize art pieces that were manipulated in a manner intended to have a consistent effect on observers' preferences or that were generally highly regarded and often, widely known (e.g., The Mona Lisa)." (p.2). They studied the effect of paintings that were not admiredartwork to reveal viewers' unbiased aesthetic experience. Their material included a set of two-dimensional artworks spanning over a variety of periods, regions, styles and genre from Fifteen to Twenty centuries, Western and Eastern works, both representational and abstract genres. The artworks were original from museums. The painting categories were "beautiful, "strange," or even "ugly." They used several different analyses and created a rich data set. They noted that aesthetic experience involves not only preference, it encompasses a variety of emotional responses ranging from "beauty to awe," sublimely and in a variety of other emotions, which are often "knowledge-based." (p.3). Their results showed highly individualized responses, meaning that viewers had very little agreement. Yet, in conclusion, they noted: "Great art is, almost by definition, universal: the wide appeal it commands comes from a connection with fundamental aspect of human nature and human cognition (Kant 1790). 
As we noted earlier, studies of the human brain response to arts have used either selfreported responses of the subjects in an experiment or by direct observation of their brain responses to visual arts stimuli.

Yet, striking similarity emerges from studies of responses to visual arts-including paintings, whether observed in fMRI studies of subjects' brains or their self-reporting responses, as the two-phase study conducted by the Walter Museum and the Center for Mind/Brain at Johns Hopkins University, has shown, Vikan (2010), et al. Dr. Gary Vikan, the Director of the Museum then, noted, "What you'll find in this show is that there is an amazing convergence. The people who came to the museum liked and disliked the same type of shapes as the people in the lab and the people in the imaging machine. It was amazing how tight the clustering was - it was like art." [Vikan, Beauty and Brain Revealed, Dana Foundation, News and Views..., October 29, 2013]. The empirical and theoretical research reviewed, jointly provide strong support that works of art are stimuli to the brain and thus affect viewers' mood, albeit differences in details. They form the theoretical pillar of our research.

With that foundation, we evaluate what Boime (2008) et al., observed in Khavarani's paintings. Describing one of his paintings_Purpose 2004 [p. 185], Boime said, “.... For Khavarani this wilderness niche is far removed from the social ills that afflict the public sphere, but it offers a model of his particular destiny. One's purpose may be held in secret, while expressing itself as a healing balm for the receptive perceiver." (p.184).

We attempt to determine if the Boime's interjection stands a formal test. We therefore test our a priori hypothesis_Khavarani's paintings calm viewers, and elevate their mood to a joyful state. Considering hundreds of worldwide affirmations, including many from patients at the Beverly Hills Cancer Center, where several of Khavarani's paintings have been on display for many years, we strive to evaluate the legitimacy of those "informal" confirmations as well.

With that background and within the context of the theoretical and empirical literature reviewed here, we present our research method and results. Our hypothesis is to verify our a priori hypothesis that Khavarani's 'paintings have characteristics that impart positive effect on the mind of the spectators. In the following section, we discuss our data and method, followed by a summary of our findings and discussion.

\section{Data and Methodology}

We collected our data during the Art Re-Store event held by the Hammer Museum and UCLA in Westwood, Los Angeles, California, November 1-30, 2013, 10:00-20:00, daily. The venue was an art district, with several galleries in close proximity to each other, one of which was Khavarani's gallery, exclusively housing his paintings. A team of trained 
volunteers asked the participants, if they were willing to partake in our research. If they agreed, received a written statement about the surveyor's academic background, and intended use of the data for an academic publication, as well as the expected time for answering the survey. They then received directions for visiting three galleries sequentially, and the process for recording their responses. Our questionnaire included six point scales for recording the direction and strength of variations in subjects' mood, illustrated pictorially, with a corresponding verbal description for each. The scales ranged from Sad, the lowest point, to Joyful, the highest. Subjects visited Khavarani's gallery, which exclusively housed his paintings, and two randomly selected galleries, in close proximity of his galley, on the same day. We used a Randomized Block Design (RBD) for collecting, organizing, and analyzing the subjects' responses.

We divided our data into two sets, because only 246 of the participant visited three galleries. We separated those who visited three galleries from those who only visited Khavarani's. Accordingly, 246 of the subjects, 82 each, are in each subgroup. We rotated these groups' sequential visits to create a Random Design Group (RDG). That model has three advantages. First, it controls for inter-group variations of responses and captures the between group variations. Second, it gives flexibility in experimental layouts. Third, it allows a better structure for implementation and administration of the survey. Table 1, identifies their tags.

Table 1: Groups and Subgroups in RDG Model

\begin{tabular}{|l|l|l|l|}
\hline Group Code & Subgroup 1 & Subgroup 2 & Subgroup 3 \\
\hline Group A & Gal A1 & Gal AK & Gal A3 \\
\hline Group B & Gal BK & Gal B2 & Gal B3 \\
\hline Group C & Gal C1 & Gal C2 & Gal CK \\
\hline
\end{tabular}

Our materials included the content of the galleries subjects visited and our Survey Instrument. We include few of Khavarani's paintings, which were on exhibition during our survey month. Multilayers in his paintings, particularly when subjects wore stereoscopic glasses, invoked many viewers' WOWs and/or AHA moments. 


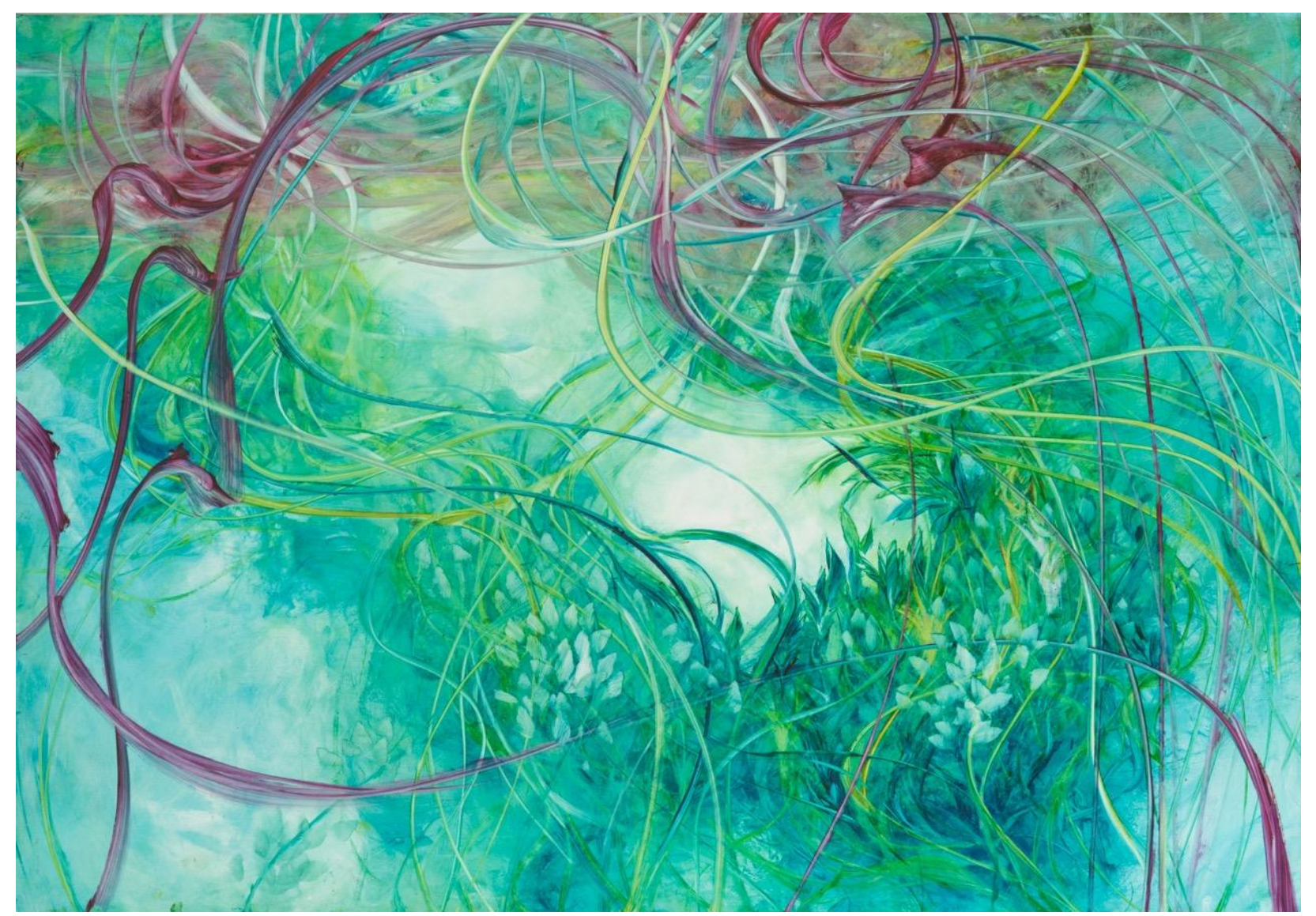

\section{L13WW_Freedom}




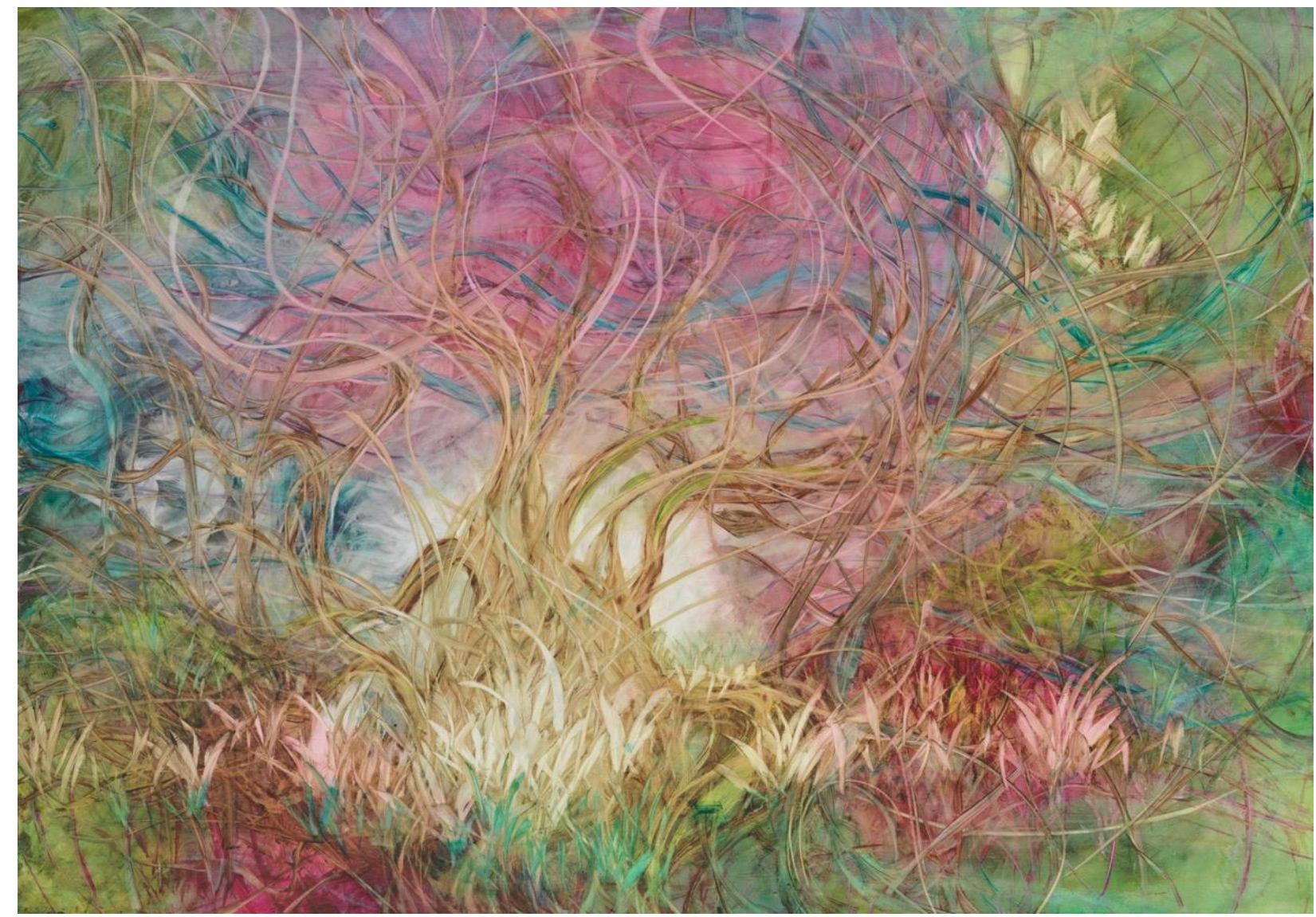

\section{L13WW_Tree of Life}




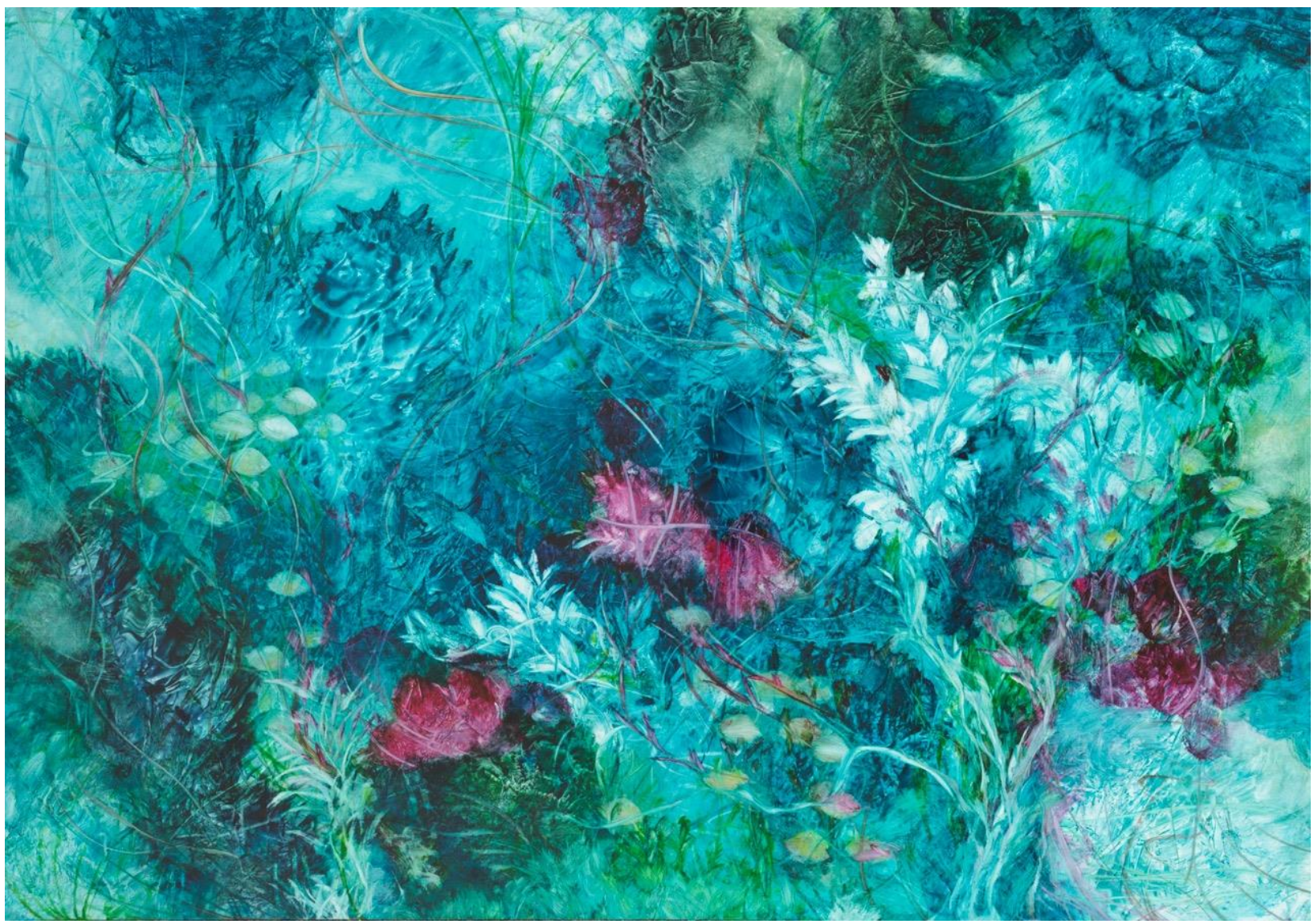

004L13WW_Unveiling

Our survey template included six pictorial scales and their respective descriptive scales for recording participants' mood, ranging from sad to Joyful. We coded these scales in numerical interval, 0-10. As we noted above, our questionnaire included an even number of scales (six Likert scales). We excluded a mid-point scale to ensure a more accurate response by avoiding "social desirability" bias arising from respondents' desire to please the surveyors.

Garland (1991).

Our data show NO shifting to the upper scales, due to omission of a center scale, as a possibility, which Garland suggested. Furthermore, we submit that our data support Worcester and Burns (1975), which concluded that people's response to a balanced Likert type scale (without a midpoint) is content-specific.

\section{Models and Statistical Results}

To determine the appropriate models for testing our hypothesis, we evaluated the Kernel Density Functions (KDF), and all basic statistics for all our groups and their histograms. They encompass more than 30 graphs and numerous regression tables. We therefore, report a summary of our results. Other data are available upon request. 
Overall, our regressions statistics illustrate a striking contrast between the affects of the content of the two random galleries included in our sample and Khavarani's-his paintings. Viewers of the other galleries' content experienced either a neutral or negative effect (in one case -59\%) on their mood after their visits. In a sharp contrast, 70\%-92\% of Khavarani's cases reported maximum Joy. Subjects' open-ended comments often uttered an AHA moment or WOW, when they viewed Khavarani's paintings. Many comments included additional observations on the affects of his paintings, for example, "moved me into a state of meditation and tranquility." Formally, we test the conjecture that Khavarani's painting has artistic characteristics that impart positive aesthetic effects on individual's mental state.

The first set of the regressions includes the Freidman test for Groups A, B and C. Their $\chi^{2}$ values are: $152.74,132.05$ and 146.97 , respectively, (all with asymptotic significance of 0.00 ). They are all well over the critical value of 12.838 for $95-100 \%$ confidence level. We reject the null hypothesis in all cases; and concluded with high confidence levels that the effect of Khavarani's paintings on viewers' mood unambiguously differs from "others" our subjects viewed.

Aside from the above three groups, our data gives us the flexibility to consider four (4)

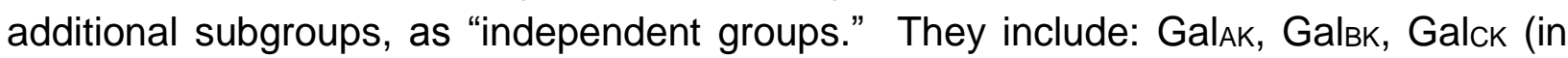
Table 1) and those who only visited Khavarani's gallery, tagged Galкк. We labeled this cluster as Group D. All subjects in D subgroups are "independent, " yet not of equal size, since Galkk has only 72 subjects, the other three have 82 , each. These data meet the requirements for the Mann-Whitney and Kruskal-Wallis models. We used both, which are equivalence of the ANOVA test. These tests generated pairwise comparisons for our subgroups in D. The Kruskal-Wallis model includes also an ad hoc test, which controls for stochastic dominance within the subgroups.

For the Mann-Whitney tests, the Chi-Squares for all pairs are below the critical value of 12.838, and their respective asymptotic significances are below 0.05 for GalBk vs. GalkK and Galck vs. Galkk. Therefore, they are very highly significant. One exception is that value for the GalAk vs. Galkк pair. That asymptotic significance is more than twice as large, thus statistically less significant. In all three cases, we retain the null hypothesis that the subjects who viewed Khavarani's paintings had the same distribution. We present the Mann-Whitney results in Table 2. 
Table 2: Mann-Whitney (and Wilcoxon) Tests

\begin{tabular}{|c|c|c|}
\hline Population Group & X2 vs. Critical Value & $\begin{array}{l}\text { Ho: Groups have same } \\
\text { distribution }\end{array}$ \\
\hline Gal $_{\text {AK vS. GalkK }}$ & $\begin{array}{l}-2.438<-1.96 \\
\text { asymptotic significance } \\
\text { tailed), } 0.115\end{array}$ & Retain \\
\hline GalBK vs. GalkK & $\begin{array}{l}-3.196<-1.96 \\
\text { asymptotic significance } \\
\text { tailed), } 0.001\end{array}$ & Retain \\
\hline Galck vs. GalkK & $\begin{array}{l}-2.905<-1.96 \\
\text { asymptotic significance } \\
\text { tailed), } 0.004\end{array}$ & Retain \\
\hline
\end{tabular}

We then used the Kruskal-Wallis test. This test extends the Mann-Whitney test by also examining the presence of stochastic dominance within the groups. Again, in all cases we retain our null hypothesis. We summarize the results in Table 3.

Table 3: The Kruskal-Wallis Statics (extends the Mann-Whitney test)

\begin{tabular}{|c|c|c|}
\hline Population Group & X2 vs. Critical Value & $\begin{array}{l}\text { Ho: Groups have same } \\
\text { distribution }\end{array}$ \\
\hline Gal $_{A K}$ vS. GalKK & $\begin{array}{l}5.945<12.838 \\
\text { asymptotic significance, } 0.015\end{array}$ & Retain \\
\hline GalBK vs. GalkK & $\begin{array}{l}10.212<12.838 \\
\text { asymptotic significance, } 0.001\end{array}$ & Retain \\
\hline Galck vs. GalkK & $\begin{array}{l}8.441<12.838 \\
\text { asymptotic significance, } 0.004\end{array}$ & Retain \\
\hline $\begin{array}{l}\text { Gal }_{A K}, \text { Gal } \\
\text { GalKK }_{\text {KK }} \text { GalcK, }\end{array}$ & $\begin{array}{l}11.121<12.838 \\
\text { asymptotic significance } 0.011\end{array}$ & Retain \\
\hline
\end{tabular}

We have shown that Mann-Whiney and Kruskal-Wallis tests unambiguously reaffirm our main hypothesis.

Furthermore, we considered a basic comparative data, which show sharp contrasts between the groups in Khavarani's subgroups, Galak, GalBK and Galck, and others. For example percentages of positive effects for those subgroups were $63 \%, 72 \%$ and $65 \%$, respectively, compared to $-59 \%$ for $\mathrm{Gal} \mathrm{B}_{2}$. More pronounced is the effect on subjects who only visited his gallery (GalkK), at 93\%. Clearly, these comparisons show that Khavarani's paintings evoked higher emotional responses in subjects, also in relative terms. 
In summary, our results, individually and collectively, strongly support our main hypothesis. We therefore, conclude with high confidence levels that Khavarani's paintings unambiguously affect viewers' emotion, as if they were "maximizing the utility of the moment," being disengaged from their outside world, as Vartanian and Skov (2014) hypothesized for cases of brain scans they studied.

\section{Conclusion}

In this research we have examined the aesthetic effect of a genre of painting known as Abstract Romanticism on individual's mental state. UCLA Professor, Albert Boime, first discovered this new style of painting and critiqued its painterly characteristics in The Birth of Abstract Romanticism, Art for a New Humanity, Rumi and The Paintings of Kamran Khavarani, (2008). We have tested the hypothesis that Khavarani's painting has artistic characteristics that impart positive affects on individual's mental state. Our data set includes survey of 318 randomly selected subjects. Their responses were recorded in Likert scale and numerically for our quantitative analyses. For ANOVA, we have used the Friedman tests (general and ad-hoc tests) for analysis of ANOVA for three randomly groups of 82 subjects. In all cases, Chi -squares rejected the null hypothesis at $95-100 \%$ confidence levels. These results strongly suggest that Khavarani's paintings have a different effect on viewers than others in our sample. They affect the viewers' brains and thus their psyche.

We have considered related multidisciplinary literatures. The gap in these literatures are as follows: First, we notice a heavy reliance on $\mathrm{fMRI}$ method of analysis and absence of statistical analyses of the survey of viewers for modeling the effect of paintings (or other forms of visual arts) on subjects' mind. The joint study of Johns Hopkins-Walter Art Museum survey, is a unique attempt for filling that gap. We have not, however, found a publication record for their seminal study. Second, all fMRI-based studies are comprised very small observations (generally 8-22 cases), and thus subject to the small sample bias, on the one hand. Third, our research is the first empirical study of a major book in the field of the Art History [Boime, 2008], and the very first study of the aesthetic affect of Khavarani's genre of painting, Abstract Romanticism, that became the subject of Boime's elaborate analysis. Fourth, this research opens the possibility of better understanding of the rational choice theory, in the context of Behavioral Economics. Carmerer (2003), addressing the notion of bounded rationality, proposed by Alfred Marshal. Marshal (1921).

This research reverberates Eric Kendal's observation in the Age of Insight, who says: "When we look at a beautiful work of art, our brain assigns different degrees of meaning to various shapes, colors, and movements we see...." [ebook, elSBN:978-1-58836-9307, Page 5380]. 
Ishizu and Zeki (2011), in The Brain Theory of Beauty, explain how the human brain reacts to the beauty (or ugliness) of paintings (and music). In a different context, Zeki (1999) notes that "... Because all art obeys the laws of the visual brain, it is not uncommon for art to reveal these laws to us, often surprising us with the visually unexpected."

The method of our data collection and their reiterations, our large sample size and highly stable statistical results, lend a robust support for our external validation of our sample. Simply put, we propose that the 318 viewers of Khavarani's paintings in our sample are representative of the population at large.

On the light side of evidence, we have examined hundreds of testimonials from viewers of Khavarani's paintings, attesting the evocative affects of his paintings on them. Our formal results, withstanding hundreds of testaments, strongly support the hypothesis that Khavarani's paintings affect the viewer's psyche, and perhaps as Vartanian and Skav (2014) suggested, when receptive subjects view his paintings, they "maximize the utility of the moment" and "disengage" from their external world, and experience a joy similar to meditative joy.

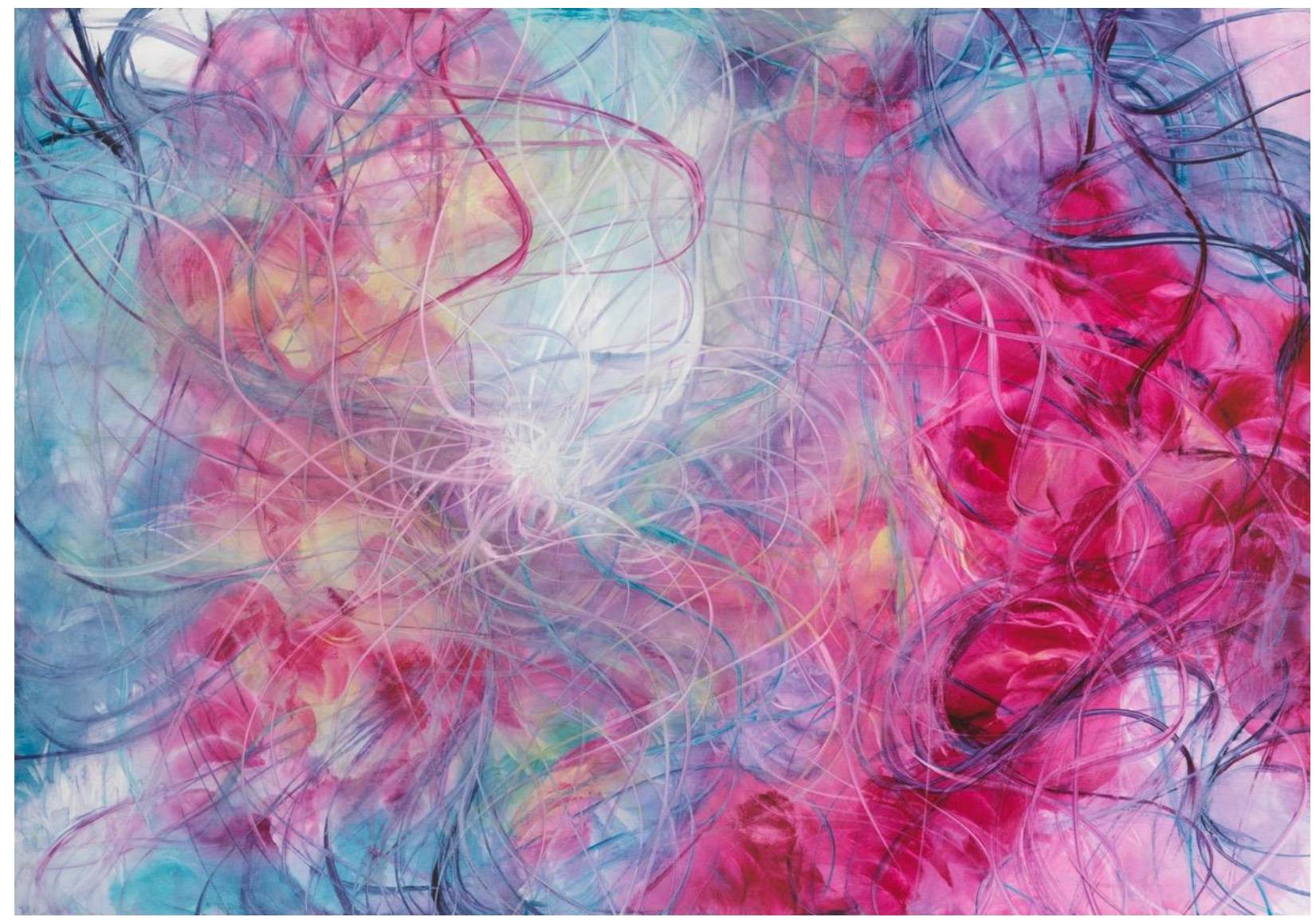

007L13WW_The Beginning 


\section{References}

Aczel, A. D. and Sounderpandian, J. (2006). Complete Business Statistics, $6^{\text {th }}$ Edition, 2006, McGraw -Hill, Irwin Series, Operations and Decision Sciences.

Anjan, C. and Vartanian, O. (2011). Neuroaesthetics, Trends in Cognitive Sciences. Vol. 18, No. 7., 37075.

Berlyne, D. E. (1971). Aesthetics and Psychobiology, Century Psychology Series, Appleton Century-Crofts. Educational Divisions, New York.

Berlyne, D. E. (1974). The new experimental aesthetics. In D. E. Berlyne [Ed.]. Studies in the new experimental aesthetics, 1-25. Washington D.C: Hemisphere.

Boime, A. (2008 a). The Birth of Abstract Romanticism, Art for a New Humanity, Art for a New Consciousness, Rumi and the Paintings of Kamran Khavarani. Sybil City Book Company, San Francisco, CA. ISBN: 978-0-9816739-2-9, Collector's Edition.

Boime, A. (2008b, July 28). From the Desk of Albert Boime, Department of Art History, UCLA. http://albertboime.com/Letters.cfm Retrieved 11/11/2015.

Burgaso, G. (2014). http://mic.com/articles/106504/science-shows-that art-is having fantastic effects on our brains and bodies Retrieved August 1, 2015.

Carmerer, C. F., G. Loewenstein and M. Rabin. (2003). (ed.). Advances in Behavioral Economics (The Roundtable Series in Behavioral Economics) [Print Replica] Kindle Edition.

Cela-Conde, C., and associates. (2004). Activation of the prefrontal cortex in the human visual aesthetic perception. Proceedings of the National Academy of Sciences the United States of America. 101(16), 6321-6325 (Published online before print April 12, 2004, doi: 10.1073/pnas.0401427101.) PNAS April 20, 2004 vol. 101 no.16 6321- 6325.

Cupchik, G. C. (2009). Viewing Artworks: Contributions of Cognitive Control and Perceptual Facilitation to Aesthetic Experience. Brain and Cognition, 70 (16), 84-91.

Daniel, Wayne W. (1990). "Kruskal-Wallis one way analysis of variance by ranks". Applied Nonparametric $\begin{array}{llll}\text { Statistics } \quad \text { (2nd } & \text { Boston: } & \text { PWS-Kent. 226-234 }\end{array}$ [http://psych.unl.edu/psycrs/handcomp/hckw.PDF Retrieved 11/18/15]

Danto, A. C. (1983). The Transfiguration of the Commonplace, A Philosophy of Art. Harvard University Press.

Dutton, D. (2009). The art Instinct: Beauty, Pleasure and Human Evolution, Bloomsbury Press, New York.

Gopnick, B. (2012).Aesthetic science and artistic knowledge. Aesthetic Science: Connecting Minds, Brains and Experience (Shimamura, A.P. and Palmer, S.E., eds). 129-159, Oxford University Press.

Holt, J. (2013). Neurasthenics and Philosophy, SAGE Open, July-September 2013: 1-7. DOI: 10.1177/2158244013500677sgo.sagepub.com. Retrieved 8/31/15.

Hager, M., Hagman, D., Danner. D. and Schankin, A. (2012). Assessing Aesthetics Appreciation of Visual Artworks-the Construction of the Art Reception Survey (ARS), Psychology of Aesthetics, Creativity and the Arts. Vol. 6(4), Nov 2012. 320-333.

Ishizu, T., Zeki, S. (2011). Toward A Brain-Based Theory of Beauty. PLoS ONE 6(7): e21852. doi:10.1371/journal.pone.0021852. Retrieved August 2, 2015.

Kandel, E. (2012). The Age of Insight. Random House, Inc. New York.[The Age of Insight: The Quest to Understand the Unconscious in Art, Mind, and Brain, from Vienna 1900 to the Present. Kindle Edition]

Kemp, S.W.P. and Cupchik, G.C. (2007). The Emotionally Evocative Effects of Paintings. Visual Arts Research, 33 no 1, 72-82.

Lacey, S., Hagtvedt, H. van essa, M., Anderson, A., Randal, S. (2011). Art for reward's sake: Visual art recruits the ventral striatum. Neurolmage, 55.1. ProQuest Psychology Journals. Retrieved $7 / 30 / 2015$. 
Marshall, A. (1920). Principles of Economics (Revised ed.). London: Macmillan; reprinted by Prometheus Books. ISBN 1-57392-140-8.

Ramachandran, V.S. and Hirstein, W. (1999). The Science of Art: A Neurological Theory of Aesthetic Experience. Journal of Consciousness Studies, 6, No. 6-7,15-51.

Reber, R., Schwarz, N. and Winkielman, P. (2004). Processing Fluency and Aesthetic Pleasure: Is Beauty in the Perceiver's Processing Experience? Personality and Social Psychology Review. Vol. 8, No. 4, 364-382.

Tsikiura, T. and Cabza, R. (2011). Remembering beauty: Roles of Orbitofrontal and hippocampal regions in successful memory encoding of attractive faces, Neurolmage, 54, 1, 653-660.

Silvia, P.J. (2005). Emotional Responses to Art: From Collation and Arousal to Cognition and Emotion. Review of General Psychology. Vol. 9, No. 4, 342-357

Silvia, P.J. and Brown, E.M. (2007). Anger, Disgust, and the Negative Aesthetic Emotions: Expanding an Appraisal Model of Aesthetic Experience, Psychology of Aesthetics, Creativity, and the Arts. Vol. 1, No. 2, 100-106.

Sklar, M. (1999). Student Problem Solving Guide for Use with Complete Business Statistics, Aczel, A., $2^{\text {nd }}$ Edition.

Vartanian, O. and Skov, M. (2014). Neural correlates of viewing paintings: Evidence from a quantitative meta-analysis of functional magnetic imaging data.Brain and Cognition, 87, 52-56.

Vessel, E., Starr, G. and Rubin, N. (2013). Art reaches within: aesthetic experience, the self and the default mode network, Frontier in Neuroscience. 7. 258.

Vikan, G. (2013). "Beauty and Brain Revealed," Dana Foundation, News and Views...,October 29, 2013.

Zaidel, D.W. (2005). Neuropsychology of Art: Neurological. Cognitive and Evolutionary Perspectives. Psychology Press, Hove, UK.

Zeki, S. (1999). Inner Vision: An Exploration of Art and the Brain. Oxford University Press, 1999. Chapters 1-3. 